\title{
BMJ Global Health Access to paediatric surgery: the geography of inequality in Nigeria
}

\author{
Mohamed Abd salam El Vilaly, ${ }^{1}$ Maureen A Jones, ${ }^{1}$ Makela Cordero Stankey (D) ,2 \\ Justina Seyi-Olajide (D) , ${ }^{3}$ Bisola Onajin-Obembe, ${ }^{4}$ Andat Dasogot, ${ }^{5}$ \\ Stefanie J Klug, ${ }^{6}$ John G Meara, ${ }^{7}$ Emmanuel A Ameh (1) , 8,9 Olabisi O Osagie, ${ }^{10}$ \\ Sabrina Juran ${ }^{6,11}$
}

To cite: El Vilaly MAsalam, Jones MA, Stankey MC, et al. Access to paediatric surgery: the geography of inequality in Nigeria. BMJ Global Health 2021;6:e006025. doi:10.1136/ bmjgh-2021-006025

Handling editor Seye Abimbola

- Additional supplemental material is published online only. To view, please visit the journal online (http://dx.doi.org/10. 1136/bmjgh-2021-006025).

Received 18 April 2021 Accepted 30 September 2021

\section{Check for updates}

(c) Author(s) (or their employer(s)) 2021. Re-use permitted under CC BY-NC. No commercial re-use. See rights and permissions. Published by BMJ.

For numbered affiliations see end of article.

\section{Correspondence to}

Dr Sabrina Juran;

sabrina_juran@hms.harvard. edu

\section{ABSTRACT}

Background About 96.3 million children and adolescents aged $0-19$ years reside in Nigeria, comprising $54 \%$ of the population. Without adequate access to surgery for commonly treatable diseases, many face disability and increased risk of mortality. Due to this population's unique perioperative needs, increasing access to paediatric surgical care requires a situational evaluation of the distribution of paediatric surgeons and anaesthesiologists. This study's aim is to identify the percentage of Nigerian youth who reside within 2 hours of paediatric surgical care at the state and national level.

Methods The Association of Paediatric Surgeons of Nigeria and the Nigeria Society of Anaesthetists provided surgical and anaesthesia workforce data by state. Health facilities with paediatric surgeons were converted to point locations and integrated with ancillary geospatial layers and population estimates from 2016 and 2017. Catchment areas of 2 hours of travel time around a facility were deployed as the benchmark indicator to establish timely access.

Results Across Nigeria's 36 states and Federal Capital Territory, the percentage of Nigeria's $0-19$ population residing within 2 hours of a health facility with a paediatric surgical and anaesthesia workforce ranges from less than $2 \%$ to $22.7 \%-30.5 \%$. In 3 states, only $2.1 \%-4.8 \%$ of the population can access a facility within 2 hours, 12 have $4.9 \%-13.8 \%$, and 8 have $13.9 \%-22.6 \%$.

Conclusion There is significant variation across Nigerian states regarding access to surgical care, with $69.5 \%-98 \%$ of Nigeria's 0-19 population lacking access. Developing paediatric surgical services in underserved Nigerian states and investing in the training of paediatric surgical and anaesthesia workforce for those states are key components in improving the health of Nigeria's 0-19 population and reducing Nigeria's burden of surgical disease, in line with Nigeria's National Surgical, Obstetrics, Anaesthesia and Nursing Plan.

\section{INTRODUCTION}

Surgical care is an indivisible, indispensable part of healthcare, with an estimated onethird of the total global burden of disease attributed to surgically treatable diseases. ${ }^{1}$ The significant portion of surgically treatable

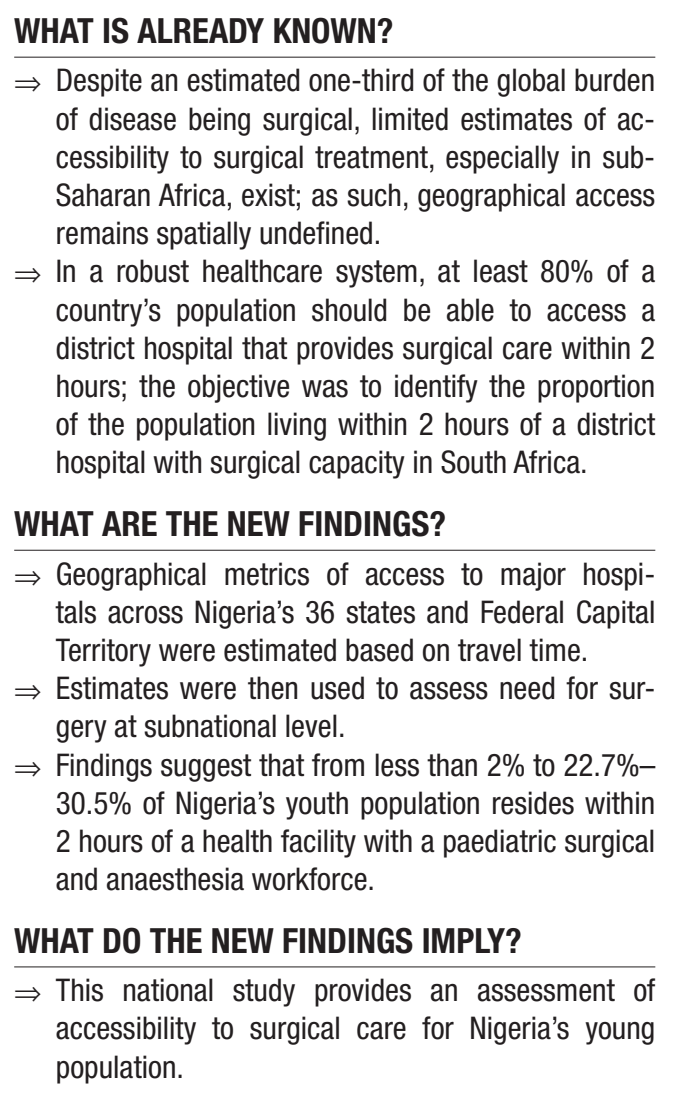

diseases in the overall global health burden places immense scrutiny on global access to surgical care. Globally, approximately 5 billion people lack timely access to safe and affordable surgical care when needed. ${ }^{2}{ }^{3}$ Of those, approximately 1.7 billion are children and adolescents and 453 million are children under 5 years of age. ${ }^{14}$ Yet, globally, low/ middle-income countries (LMICs) account for only $6 \%$ of the world's annual surgical procedures. $^{5}$ Furthermore, according to the Lancet Commission on Global Surgery (LCoGS) criteria, less than $3 \%$ of the paediatric population in low-income countries and less than $8 \%$ of the paediatric population in 
lower middle-income countries have access to surgical care. $^{23}$

The lack of access for more than two-thirds of the world's population will make achieving the 2030 Agenda's Sustainable Development Goals (SDGs) exceptionally difficult. Improvements in surgical access, especially in LMICs, where health systems are frequently resource constrained, will require complex, coordinated, and evidence-based policies and initiatives. A large scale-up of child healthcare, including paediatric surgical services, is critical for improving overall healthcare access and achieving the SDGs.

In sub-Saharan Africa, the burden of surgical disease is estimated between 257.8 and 294.7 million people. The burden of surgical disease is estimated between 115.3 million and 131.8 million in children under 15 years of age. ${ }^{46}$ Almost $85 \%$ of children in LMICs will have a surgically treatable condition by the age of 15 years. ${ }^{167}$ Without requisite surgery, many children will face lifelong disability and increased mortality. Paediatric surgery has unique requirements distinct from adult surgical care, and includes particular anaesthetic, perioperative, and postoperative needs.

To efficiently and effectively scale up services, policies and initiatives must be evidence based, identifying vulnerable populations and current healthcare gaps, and ensuring that any mitigating efforts or allocation of resources are implemented where they will have the greatest impact. The supporting evidence can be derived from the recommended framework of metrics developed by the LCoGS. The framework has six core indicators that can be used to measure universal access to safe, affordable surgical care, when needed. These indicators include timely access to essential surgery, specialist surgical workforce density, surgical volume, perioperative mortality rate, protection against impoverishing expenditure and protection against catastrophic expenditure. ${ }^{8}$

This research focuses specifically on timely access to paediatric surgery. The LCoGS defines access to timely essential surgery as the proportion of the population that can access, within 2 hours, a facility that can perform the three Bellwether procedures of caesarean delivery, laparotomy and treatment of open fracture. ${ }^{2}$ Access within 2 hours is a temporal threshold as most complications from childbirth must be addressed within this time frame. ${ }^{8}$ Using the 2-hour threshold, it becomes critical to conduct health catchment area mapping that spatially defines travel times to a qualifying healthcare facility to become essential to assessing access. However, comprehensive accessibility analyses that aim to truly define access must also account for numerous other dimensions, including, but not limited to cultural, quality and financial dimensions. ${ }^{1}$ Previous models based on spatially defined travel times estimated that $92.5 \%$ of the population located in sub-Saharan Africa resided within 2 hours of a major hospital catchment area. These estimates resulted in a regional burden of surgical disease between 257.8 million and 294.7 million people, with an estimated burden of surgical disease in children younger than 15 years of age that was 115.3-131.8 million and a similar spatial distribution when compared with the total population. ${ }^{4}$ This paper will assess and display the spatial access to paediatric surgical care by integrating novel methods, improving the geospatial outputs and depicting an overall more realistic and accurate accessibility analysis.

Nigeria comprises 36 states and its Federal Capital Territory (FCT), Abuja, each with populations, economic profiles and budgets comparable with small countries. Nigeria's overall development is predominantly determined by state-level dynamics rather than by nationallevel decision-making. The 36 states and the FCT are politically classified into six geopolitical zones, each developed to reflect the unique cultural, historical, ethnic and economic characteristics of the states in that region. Therefore, political analysis was considered to highlight the stark differences in paediatric surgical access across Nigeria's political zones. ${ }^{9}$

The Federal Republic of Nigeria is the world's seventh most populous country. The United Nations World Population Prospects lists Nigeria's 2020 population at 206 140000 people, with a population growth rate of $2.59 \%$ between 2015 and 2020. Current population projections estimate that Nigeria will have 300 million people by 2040 and more than 400 million by $2050 .{ }^{10}$ If these projections hold true, Nigeria will become the third most populous country in the world. In terms of urbanisation rates, Nigeria's urban population as a percentage of the total population has continuously increased since 1950, to $52 \%$ in 2020 . That places Nigeria's urban population at the higher end, compared with the urban population in the subregion (Western Africa 47.7\%) and region (Africa 43.5\%). ${ }^{11}$

Proportionally, children and adolescents represent the largest proportion in the Nigerian population. Children between the ages of 0 and 14 years account for $43.5 \%$ of the total population. Children and young people under the age of 19 years of age represent $54.1 \%$ of Nigeria's population. ${ }^{9}$ Furthermore, Nigeria accounts for $20 \%$ of all births on the African continent and $5 \%$ of the global total. Based on current projections, by 2050, 1 of every 13 births in the world will occur in Nigeria. ${ }^{10}$ In 2018, Nigeria had the second highest burden of death among children under 5 years of age annually (866 deaths per year) in the world, with a medium under-5 mortality rate (U5MR) of 120 deaths per 100000 live births. ${ }^{12}$ U5MR strongly correlates with socioeconomic and geographical characteristics; U5MR decreases as the household wealth index and the mother's education level increases. In Nigeria, both of these rates were highest in rural areas and in the north west geopolitical zone. ${ }^{13}$ Despite the large proportion of children, access to paediatric care, specifically paediatric surgical care, is limited, evidenced by a workforce deficit of 693 for children $<15$ years in $2015 .^{14}$ 


\section{METHODS}

The accessibility analysis drew on five datasets that were integrated to model access to health facilities providing paediatric surgery and anaesthesiology services. The five datasets used in this analysis included (1) number of paediatric surgery and anaesthesiology care providers by location, (2) gridded modelled population estimate data at $100 \mathrm{~m}$, (3) digital elevation model at $30 \mathrm{~m}$, (4) road networks and (5) river networks.

\section{Patient and public involvement}

The development of the research question and outcome measures was informed by consultations within the political process of the National Surgical, Obstetrics, Anaesthesia and Nursing Plan for Nigeria (NSOANP) ${ }^{15}$ without direct involvement of the patient. No patient survey was conducted nor were inputs received by patients.

As a component of the baseline assessment for the NSOANP, workforce data on paediatric surgery and anaesthesiology care physicians were obtained from the Association of Paediatric Surgeons of Nigeria and Nigeria Society of Anaesthetists. The data were collected from various sources including the published directory of the Nigerian Society of Anaesthetists (2016), data from the Medical and Dental Council of Nigeria (2018-2019), National Postgraduate Medical College of Nigeria (20192020) and published data from the West African College of Surgeons (2019-2020), as well as personal communication with heads of anaesthesia departments of all teaching hospitals in Nigeria and personal communication with national presidents of the various professional surgical specialties. The workforce database was used for the NSOANP (2019) and is being updated annually via phone calls. Triangulation between all data sources was used to support credibility. The database that was used for the study contained information on both fully trained paediatric surgeons and trainees across the country as distributed in each state and the FCT. Updated information was obtained from the head of departments of anaesthesiology of all the teaching hospitals in Nigeria. Fully trained specialist anaesthesiologists, as well as the number and location of accredited hospitals for training physician anaesthesiologists in Nigeria, are listed and mapped. The assumption that specialist anaesthesiologists can provide paediatric anaesthesia has been made. The location of qualifying health facilities with at least one paediatric surgeon was converted into a point location.

Bottom-up gridded population estimates $^{16}$ for Nigeria were downloaded from the website of the GeoReferenced Infrastructure and Demographic Data for Development (GRID3) project, ${ }^{17}$ including gridded population estimates from 2016 to 2017 at $100 \mathrm{~m}$ by 100metre gridded cells with national coverage for Nigeria, along with disaggregated age and sex estimates. Each gridded raster contains estimates of total population size for each approximately 100-metre gridded cell across Nigeria. The GRID3 Nigeria gridded model population estimates represent the timeliest data of the population's

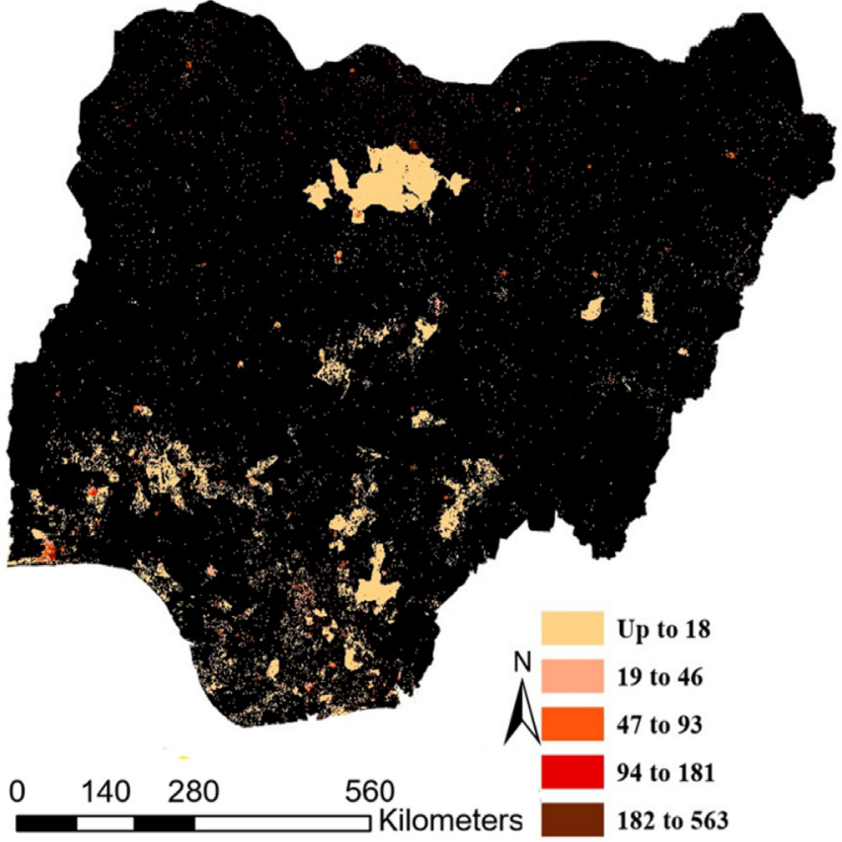

Figure 1 Spatial distribution of total gridded paediatric population (0-19 years of age) density per $100 \mathrm{~m}^{2}$.

distribution across the country, at very high resolution. Although population and housing censuses are the most important resource to producing accurate population data at the national and subnational level, the most recent census in Nigeria was conducted in 2006. GRID3 data are used in this analysis to compensate for the lengthy gap in actual data collection since. GRID3's model population methodology is found elsewhere. ${ }^{18}$ For this analysis, the population data and all raster layers were assembled at a spatial resolution of 100 by $100 \mathrm{~m}$, a resolution of 3 arc (approximately $100 \mathrm{~m}$ at the equator) and the projection fit within the Geographic Coordinate System, WGS84. The gridded population estimates of paediatric age from 0 to 19 years of age and by sex were extracted. The authors followed the guidelines by the Nigerian's Ministry of Health in terms of the paediatric population universe.

Figure 1 demonstrates the density of the paediatric population defined as those $0-19$ years of age per $100 \mathrm{~m}^{2}$. Density ranges between 0 and 563 persons per $100 \mathrm{~m}^{2}$. Urban residential centres correlate with highest paediatric population density. In online supplemental figure $1 \mathrm{a}-\mathrm{c}$, the areas in black indicate commercial centres in urban areas or unsettled areas with no paediatric population present. These figures highlight these geographical blind spots across the country, further elucidating the level of urbanisation and settled areas across the national territory.

Topographical information including elevation, land cover and land use at high spatial resolution was used to demarcate Nigeria's topographical characteristics. Using a digital elevation model (DEM) allows for the integration as slope as one of the main topographical factors impacting the speed of human movement across space. 
The DEM at $30 \mathrm{~m}$ is based on the Advanced Spaceborne Thermal Emission and Reflection Radiometer (ASTER) Global DEM (ASTER Validation Team, 2009). ${ }^{19}$

The road network data layer was generated through an extraction of roads from OpenStreetMap, ${ }^{20} 2018$ and the United Nations Office for the Coordination of Humanitarian Affairs: The Humanitarian Data Exchange. ${ }^{21}$ This layer includes the most recent georeferenced roads, streets and pathways in Nigeria. For this analysis, the road networks were classified into four main categories based on the road conditions: residential area, primary, secondary and tertiary roads. Further, motorised transport was used in the analysis of travel times along these major roads.

The river network data layers were generated from HydroSHEDS database. ${ }^{22}$ These data provide hydrographical information in a consistent and comprehensive format for regional and global-scale applications.

The recent availability and use of geospatial data have enabled the sophisticated evaluation of service access. Through the use of geospatial data, one can calculate the shortest time or distance from any location on earth to another. These calculations include combining the distance travelled on different road surfaces with an impedance measure (ie, rivers or geographical faults), which accurately reflects the speed an individual can travel on different qualities of roads and on the slope of the terrain through which the road passes.

To connect every person with the closest paediatric surgeon and anaesthesia provider, this analysis used a series of accessibility indicators. The inclusion of indicators accounts for the notion that accessibility is not a discrete variable (ie, to have or not have access), but a continuum that reflects the difficulties that each individual may encounter when accessing various infrastructure types. For this analysis, access was defined as how feasible it is to physically reach a qualifying facility, considering factors such as distance, type of transportation and time. The main assumption was that individuals are likely to move through highways, major roads or paths when those exist. It was also assumed that in the absence of major roads or paths, an individual would walk to access the nearest facilities. The final objective was to calculate the time a person requires to access the nearest qualifying health facility through the fastest route.

The moving time on the land surface depends on various factors, the most important being the distance. Other critical factors include the existing road network with its specific characteristics, the terrain's slope, and the presence of obstacles or barriers, such as rivers (except for cases in which rivers are used as ways of transport). This study's methodology consisted of three steps: in the first step, the travel time required to reach the nearest facility was calculated; in the second phase, the catchment areas around these facilities were generated; in the third step, the population within each catchment area was extracted.
Travel time calculations using motor vehicles were conducted for four main types of roads, assigning an average speed to each road type. The projected speed for residential areas was $15 \mathrm{~km} /$ hour, $45 \mathrm{~km} /$ hour for primary roads, $85 \mathrm{~km} /$ hour for secondary roads and 100 $\mathrm{km} /$ hour for tertiary roads. The road network was then converted to a raster layer at 30-metre cell size.

To estimate human walking speed over cross-country terrain, this study used Tobler's Hiking Function, which has been widely used to model human movement across space. ${ }^{23}$ An equation for walking speed based on terrain slope yields walking velocity, $\mathrm{W}(\mathrm{m} / \mathrm{s})$, approximated by: $\left.\mathrm{V}=6 \times \mathrm{e}^{-3.5 \times a b s(\mathrm{~S}+0.05}\right)$, where $\mathrm{V}$ represents walking velocity $(\mathrm{km} /$ hour$)$, e means exponential, abs means absolute and $S$ equals the terrain's degree of slope $(\mathrm{dh} / \mathrm{dx})$.

Another variable accounted for in this model corresponded to the presence of natural barriers, such as rivers, which could prevent people from travelling in a straight line in the absence of a bridge. Cells corresponding to areas with a river and no bridge were assigned a speed of $3 \mathrm{~km} /$ hour.

At present, a standardised definition of geographical accessibility does not exist. Therefore, this study employed a time gradient of up to $30 \mathrm{~min}$, up to 1 hour, up to 2 hours and above 2 hours for the mapping of geographical accessibility. ${ }^{24}$ This time gradient was based on the frequent use of less or equal to 2 hours of travel time for evaluating timely access to Emergency Obstetrics and Neonatal Care services and less or equal to 1 hour of travel time for evaluating timely access to principal referral centres with cardiac catheterisation services.

The accessibility analysis was developed in a raster format by converting the entire area of analysis into gridded cells, measuring 30 by $30 \mathrm{~m}$, based on the DEMs. Each cell was assigned a friction value based on characteristics of slope, roads and natural barriers. The friction grid was then integrated into the model to run the costweighted distance algorithm over the raster surface. The cost-weighted distance algorithm calculated the accumulated time it takes to arrive at each qualifying health facility depending on departure location, replacing overlapping values with the most efficient route. In the second step, catchment areas were generated from the cost-distance grid, which contained the minimal total cost to travel from each health facility location(s) to any cell. Contour techniques were used to generate catchment areas of 0-30 $\mathrm{min}, 0-60 \mathrm{~min}, 0-120 \mathrm{~min}$ and above $120 \mathrm{~min}$ around each health facility providing paediatric surgery and anaesthesiology services. Finally, the target population was extracted by catchment areas, age, and sex to calculate the population's geographical access to paediatric surgery and anaesthesiology health workforce and services.

\section{RESULTS}

The results depict inequality in access to surgical care that is currently affecting Nigeria's child and adolescent 


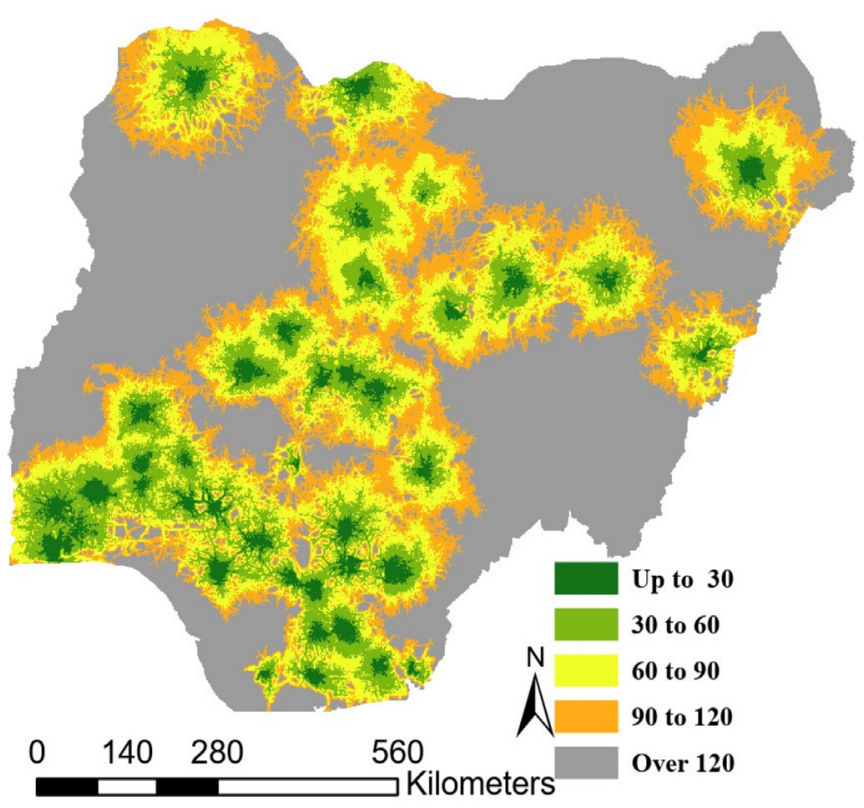

Figure 2 Travel time to a health facility with a paediatric surgeon in 30,60, 90, 120 and over 120 min increments of travel time.

population. Overall location of health centres aligns with urbanised locations, with most health centre locations correlated with major population centres, such as Lagos in Lagos state, Kano in Kano state, Ibadan in Oyo state, Benin City in Edo state, Port Harcourt in Rivers state, Jos in Plateau state, Ilorin in Kwara state and Abuja in the FCT (figure 2). Forty-eight per cent of the total population resides in rural areas and was over the 120-minute travel time indicator, as a result of the disproportionate urban clustering of qualifying health facilities.

Nigeria's population aged $0-19$ years of age is estimated to total 96.3 million young people, comprising 47.2 million girls and 49.1 million boys. Table 1 illustrates the total female and male population $0-19$ years of age within 2 hours of a health facility with a paediatric surgeon on staff, disaggregated by major age groups. Only $12.9 \%$ of this population resides within 2 hours to a facility with a paediatric surgeon. Among the age groups, lack of access is fairly evenly distributed, with ages 15-19 years experiencing the least access at only $11.7 \%$. The lack of timely access to paediatric care for $87.1 \%$ of Nigeria's young population contributes to the experienced high burden of surgical disease among this age group.

Online supplemental table 1 displays the female population 0-19 years of age who reside within a 2-hour catchment area to a health facility with a paediatric surgeon on staff compared with the total number of children in the area, categorised by major age groups and states. The total percentage of the paediatric population within a 2-hour access catchment per each age category ranges from $11.76 \%$ and $13.75 \%$ and is fairly consistent across age categories per state. However, there is significant variance in per cent of access among states, ranging between

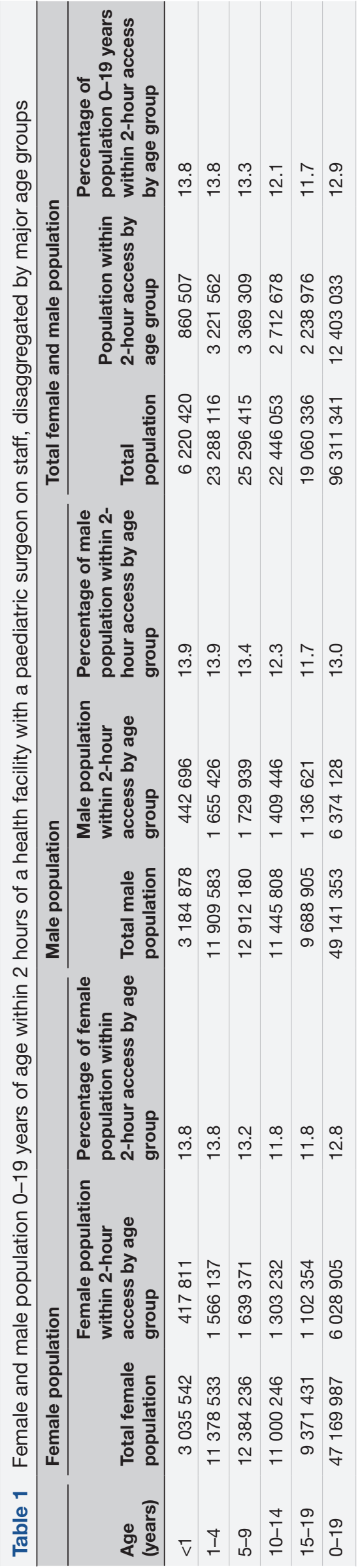




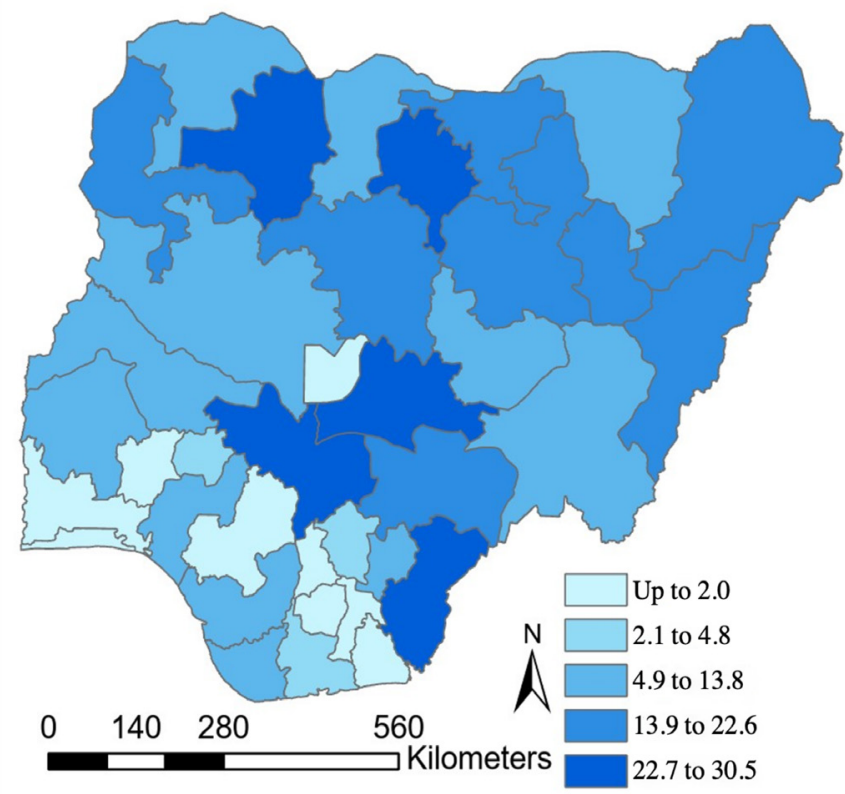

Figure 3 Percentage of population 0-19 within 2 hours of travel time to a health facility with a paediatric surgeon by state.

$0.15 \%$ (FCT, ages $1-4$ and 10-14) and 32.23\% (Kano, ages 15-19).

Online supplemental table 2 displays the male population 0-19 years of age who reside within a 2-hour catchment area to a health facility with a paediatric surgeon on staff, categorised by major age groups and state. Similarly, the total percentage of the paediatric population with access to a paediatric surgeon across age categories remains within 3 percentage points, ranging from $11.73 \%$ (ages $15-19$ ) to $13.90 \%$ (ages $1-4$ and $<1$ ), and there is significant variance in percentage accessibility across states ranging between $0.15 \%$ (FCT, ages $<1$ and $1-4$ ) and $31.41 \%$ (Zamfara, ages $<1$ and $1-4$ ). At the state level, as displayed in figure 3 and online supplemental tables 1 and 2, Zamfara and Kano states have the highest percentage of their youth population, regardless of sex, within 2 hours of travel time to a facility with at least one paediatric surgeon (approximately $30 \%$ and $30 \%$, respectively). However, in Zamfara state, this timely access is a result of the proximity of a facility with a paediatric surgical care provider located within the neighbouring federal state. Zamfara state does not have any qualifying facility located within its state borders. Imo and Osun states have the smallest crude number of population within 2 hours of travel time to a paediatric surgeon $(<1 \%$ and $<1 \%$, respectively).

This study found that in nine states, less than $2 \%$ of the target population resides within 2 hours of a health facility with a paediatric surgeon. In three states, between $2.1 \%$ and $4.8 \%$ of the target population resides within 2 hours of a qualifying facility. A total of $4.9 \%-13.8 \%$ of the population in 11 states resides within 2 hours of a travel time to a qualifying facility. In eight states, $13.9 \%-22.6 \%$ of the population resided within 2 hours and five states
$22.7 \%-30.5 \%$ of the target population resided within 2 hours of travel time to a qualifying facility. Although states such as Zamfara do not have a facility with a paediatric surgeon within the state's borders, this study found that there was still greater access than some states with facilities that have a paediatric surgeon due to the proximity of the facilities in nearby states to Zamfara's borders. Total paediatric surgery workforce includes both fully trained paediatric surgeons and paediatric surgeon trainees as shown in table 2. The 'Number of paediatric surgeons only' column indicates calculations based on only fully trained paediatric surgeons. The total number of paediatric surgeons present in a given state ranges between 0 (Tarabe, Yobe, Zamfara) and 19 (Lagos), with ratios per 100000 population ranging from 0 to 0.71 (FCT). For the 'Paediatric surgeons only' calculations, values tend to be lower across the board as trainees are excluded. Urban states (FCT, Lagos, Edo) with teaching facilities tended to have higher ratios compared with those more rural states. Some values were not calculated due to lack of availability of paediatric surgeons. Table 2 also displays the ratio of physician anaesthesia specialists to Nigeria's population between 0 and 19 years of age. Total number of anaesthesiology providers includes the reported number of consultant anaesthesiologists and trainees in a given state. The 'Number of consultant anaesthesiologists only' column indicates calculations based on only fully trained physician anaesthesiologists. The total number of physician anaesthesia specialists in Nigeria ranges from 0 in Yobe state to 168 in Lagos, with ratios per 100000 of the paediatric population, aged $0-19$ years, ranging from 0 to 4.09 (Lagos). Similar to the 'Paediatric surgeons only' column, the 'Consultant anaesthesiologists only' values tend to be lower given the exclusion of trainees in the calculations. As found in table 2, urban states (FCT, Lagos, Edo) with teaching facilities tended to have higher ratios compared with more rural states. Some ratios were not calculated due to lack of availability of the anaesthesia workforce in a given state.

\section{DISCUSSION}

Using reported provider availability along with facility location, we estimate the Nigerian youth population's physical access to surgical and anaesthesia care and evaluate the presence of Nigeria's paediatric surgery workforce at the national and state level. Nationally, our study concluded that $12.9 \%$ of the youth population between 0 and 19 years of age resides within 2-hour travel time to a facility with an available paediatric surgeon. We demonstrate significant variance in access at the state level, with the percentage of the youth population residing within 2-hour travel time to a facility with an available paediatric surgeon ranging from $0 \%$ to $30 \%$. These values fall well below the LCoGS recommended target of $80 \% .^{2}$ We demonstrate significant inequality in distribution of healthcare workforce that favours more urban centres, which is consistent with previous studies. ${ }^{16}$ At the 


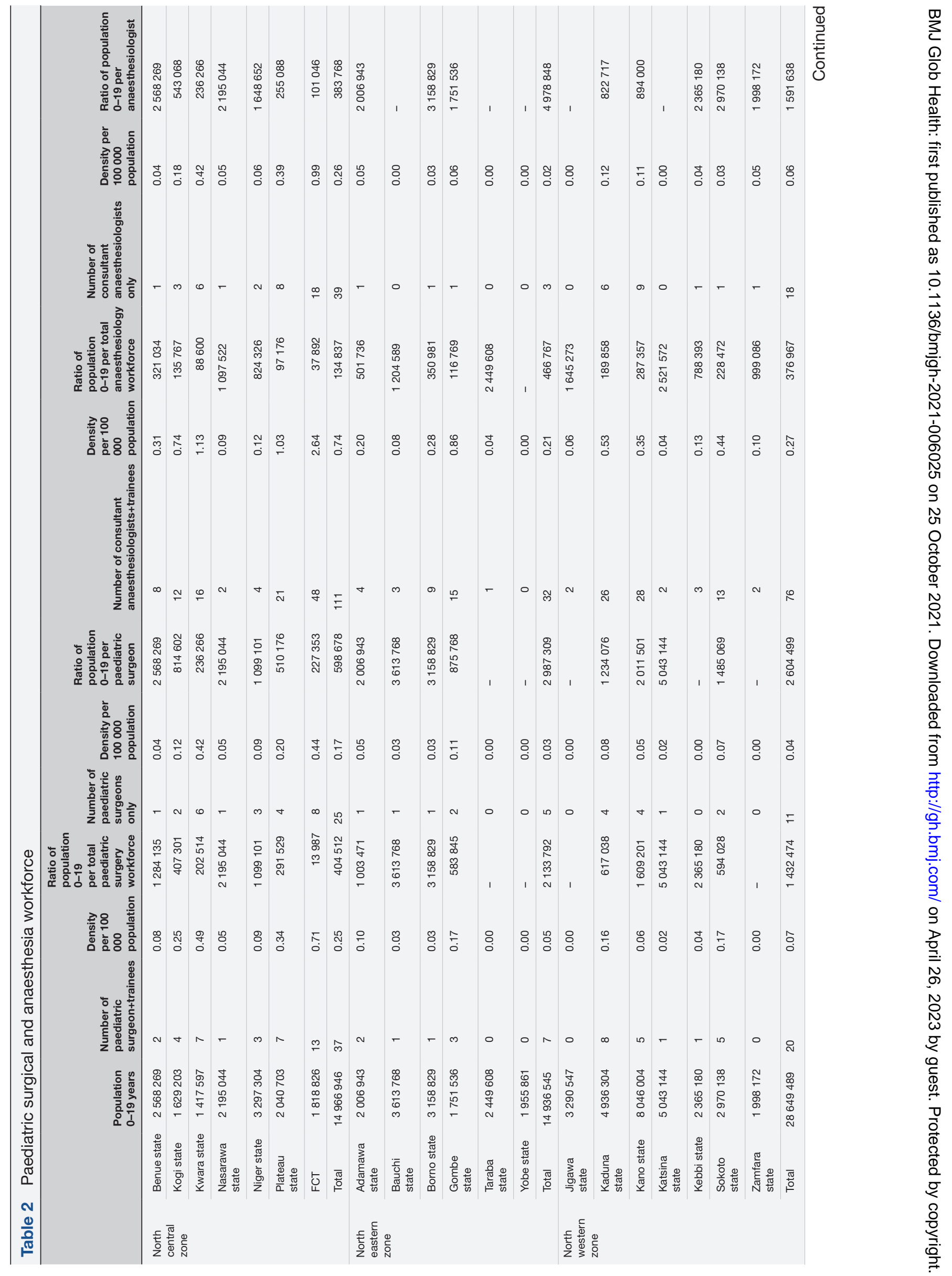




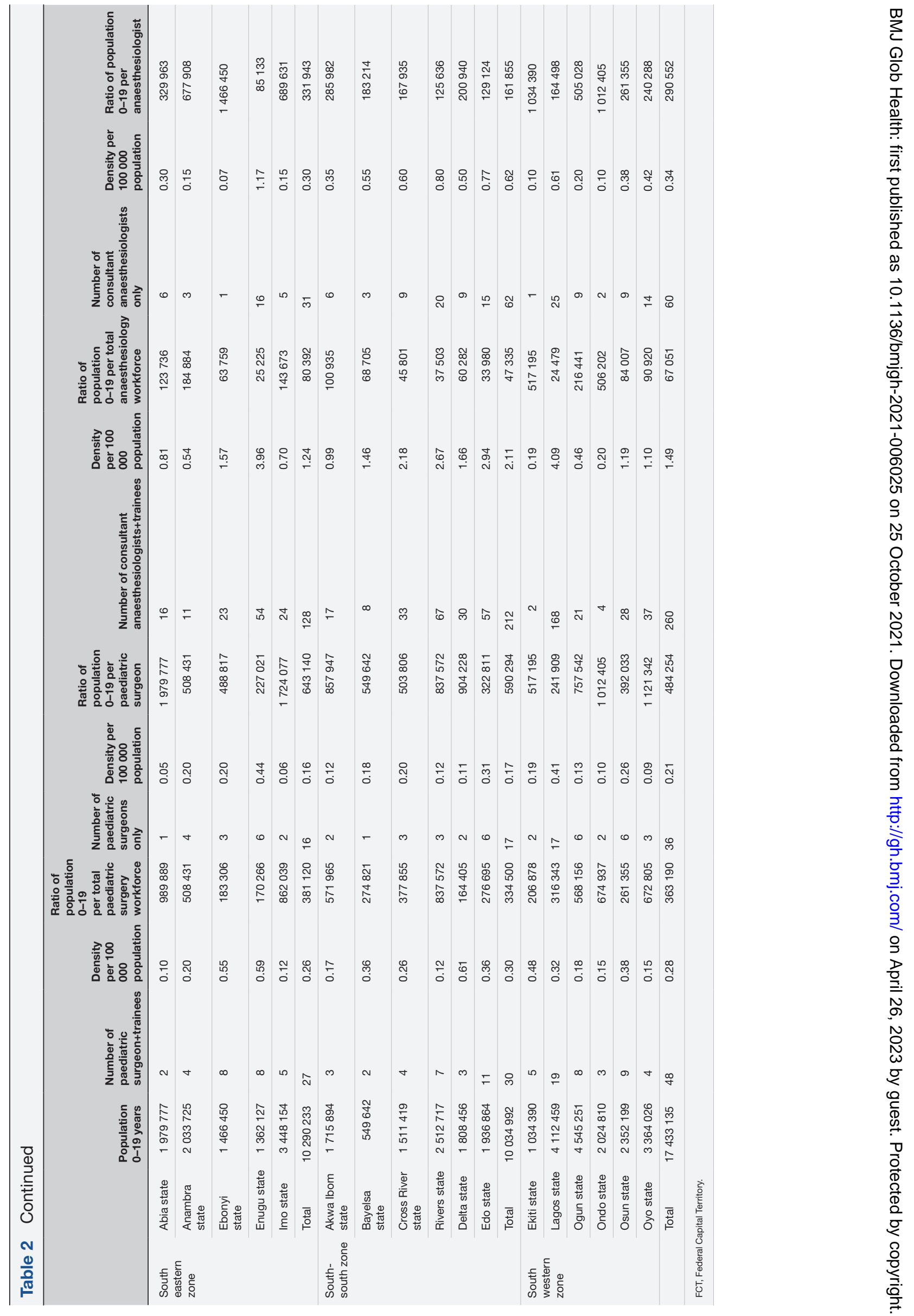


national level, we determined the overall ratio of paediatric surgeons and trainees per 100000 youth of $0-19$ years is less than 0.01 . There is evidence that 0.4 paediatric surgeons per 100000 children under 15 years of age is correlated with significant improvements in survival. ${ }^{25}$ The ratio of anaesthesiology specialists and trainees (less than 0.01 per 100000 ) falls below the World Federation Society of Anaesthesiologists recommendation of an interim goal of 5 physician anaesthesia specialists per 100 000 population..$^{26}$ It is important to note that the anaesthesiology specialist ratio is likely an overestimation, as the ratio was calculated for Nigeria's paediatric population and not the entire population of Nigeria, and the anaesthesiologists provide anaesthesiology services to both adults and young people. These findings add additional value to an earlier report ${ }^{4}$ that initially used facility location to determine geographical accessibility in subSaharan Africa.

Previous national estimates obscure subnational inequalities and vulnerabilities, and do not allow for adequate planning and investment, especially in a decentralised federal republic where states share resources at their geopolitical level. There is evidence that a higher absolute number of paediatricians in Nigeria's political zones is associated with a lower under U5MR and accounted for $84 \%$ of the variability among zones. ${ }^{14}$ For this reason, the significant variation of surgeon:youth (0-19 years population) and anaesthesiologist:youth (0-19 years population) ratios among states and political zones that we illustrated in this study is important to consider when allocating resources at the political zone level. It is important to recognise that human factors also impact how the workforce is allocated and retained in areas of need in Nigeria, such as lack of financial incentives, adverse living conditions and excessive workloads. These must be addressed in conjunction with increased workforce to improve appropriate distribution of human resources and retention. As confirmed in this study, Nigerian physicians tend to work in urban or semiurban areas for several reasons, notably due to proximity of family, proximity to their hometowns which are typically urban or semiurban, and facility availability, which may have influenced the workforce distribution we have determined via this study. ${ }^{27}$ Without improving this access, the burden of unmet surgical need in this age group would not be addressed and achieving universal health coverage and health targets of SDGs would be unlikely.

There is a further need to invest in data collection on individual barriers to care. Interventions to overcome these barriers of access to safe surgery could help to reduce negative outcomes of delayed or lack of access, such as increased morbidity and mortality rates. ${ }^{27}$ The lack of timely access to paediatric care for $87 \%$ of Nigeria's target population contributes to the experienced high burden of surgical disease among Nigeria's children. Increasing the percentage of the population who resides within 2 hours of travel time to a paediatric surgeon will be critical to improving the overall health of the Nigerian population and deliver upon Nigeria's NSOANP. The large access gaps found must be addressed in order to decrease the prevalence of life-long disabilities and increased mortality rates that arise from the lack of care for surgically treatable diseases.

The Optimal Resources for Children's Surgical Care (OReCS) created by the Global Initiative for Children's Surgery (https://www.globalchildrenssurgery.org/optimal-resources/) has provided a roadmap to facilitate the provision of children's surgical care particularly at district and first level hospitals. ${ }^{28}$ Nigeria has leveraged OReCS to incorporate children's surgical care into NSOANPs to begin to address the poor access to surgical care for children. This plan provides for the delivery of basic emergency and essential children's surgical care at district and first level hospitals, where there are no paediatric surgeons and specialist anaesthesiologists. Increasing the percentage of the population who resides within 2 hours to a paediatric surgeon will be critical to improving the overall health of the Nigerian population and deliver upon Nigeria's NSOANP. Implementation of the NSOANP has just begun and it is envisaged that it would, to some extent, improve access to this age group.

There are limitations to this study. The definition of access in this study is focused on geography and may not reflect the lived reality. Our analysis assumed that individuals are likely to move through highways, major roads or paths when those exist, and that in the absence of major roads or paths, an individual would walk to access the nearest facility. Catchment areas were developed on the assumption of motorised vehicle access and did not account for other common transportation modes, such as public transport. It is well established that access is a multidimensional construct and includes measures of geography, political, ethnic and cultural issues, timeliness, health service capacity, organisation and coordination, quality, safety, affordability and more. These dimensions are particularly important to consider in young people, who may not have the means or agency to access care on their own.

The assumptions made to determine geospatial access for the youth population are important to reiterate as limitations to this study. We assume that paediatric surgical care can only be provided by paediatric surgeons, and that anaesthesiologists can provide paediatric anaesthesia care. We also assumed that teenagers up to 19 years of age require a paediatric surgeon for their care. We used the 2-hour benchmark within which to receive emergency care per the LCoGS guidelines, under the assumption that time to emergency care is similar for adult and paediatric surgical conditions. The term 'paediatric surgeons' used throughout this manuscript was used synonymously with 'paediatric general surgeons' and there are likely other surgical specialists involved in the surgical care of children not included in this study.

A significant limitation to this study that we acknowledge is that considering only workforce data in this 
analysis. This does not necessarily indicate the true workforce availability in the facilities. For example, for this research, the assumption was made that a single paediatric surgeon in Nasarawa state is available to perform surgery at all times. We recognise that true availability of surgery in these facilities requires not just workforce, but consumables, infrastructure and more. New facility data or an in-depth facility assessment is needed to further define the needs for infrastructure, personnel, and medicine supply to achieve timely and safe, affordable surgery.

Despite these limitations, we argue that these results are an important step in determining true access: these other factors likely further limit the availability of surgical care for paediatric populations, additionally emphasising the urgency in addressing this issue.

Despite Nigeria's human and natural resources and strategic position on the continent, the country's health system lacks sufficient capacity. The inadequacies in health personnel are one component to this lack of capacity and are even more apparent in rural areas, as is demonstrated in our study. Notably, the Nigerian government has implemented numerous initiatives to address and reform some of these inadequacies, including improving staff quality, reductions in waiting time, increased provision of more affordable drugs, infrastructure investment, including the building of additional facilities, and improving the environment of facilities; however, great disparities persist. ${ }^{25}$

\section{CONCLUSIONS}

Assessing and geographically mapping an individual's travel time from their usual residence to a healthcare facility that provides paediatric surgery and anaesthesiology services is a critical component to identifying gaps in the provision of surgical care. With geospatial analyses such as these, governments and development partners can begin to formulate effective, targeted policies and programmes with the greatest impact on reducing service area gaps.

With Nigeria's growing paediatric population, Nigeria must accelerate the relevant and appropriate development of its paediatric surgical and anaesthesia workforce and surgical system overall to meet their population's growing surgical needs. Additionally, there is a need to develop a scheme to safeguard national investments spearheaded by the NSOANP, which has previously not been done by measures suggested herein. This analytical effort provides updated evidence to support the implementation of Nigeria's current NSOANP. Mapping of health access at the subnational level should be integrated into policy formulation, as well as for the monitoring of investments and programmes.

${ }^{1}$ Technical Division, Population and Development Branch, United Nations Population Fund, New York, New York, USA

${ }^{2}$ Department of Global Health and Social Medicine, Harvard Medical School, Boston, Massachusetts, USA
}

${ }^{3}$ Lagos University Teaching Hospital, Lagos, Nigeria

${ }^{4}$ Department of Anaesthesiology, Faculty of Clinical Sciences, College of Health Sciences, University of Port Harcourt, Port Harcourt, Nigeria

${ }^{5}$ Nigeria Country Office, United Nations Fund for Population Activities, Abuja, Nigeria ${ }^{6}$ Epidemiology, Department of Sport and Health Sciences, Technical University of Munich, Germany and Munich Data Science Institute (MDSI), Technical University of Munich, Germany, Munich, Germany

${ }^{7}$ Plastic and Oral Surgery, Boston Children's Hospital, Boston, Massachusetts, USA

${ }^{8}$ National Hospital, Abuja, Nigeria

${ }^{9}$ Division of Paediatric Surgery, National Hospital, Abuja, Nigeria

${ }^{10}$ Department of Surgery, University of Abuja Teaching Hospital, Gwagwalada, Abuja, Nigeria

${ }^{11}$ Program in Global Surgery and Social Change, Harvard Medical School, Boston, Massachusetts, USA

Twitter Makela Cordero Stankey @MakelaStankey, John G Meara @JohnMeara and Sabrina Juran @sabrinajuran

Contributors SJ and MAsEV conceived the original idea and were in charge of overall direction and planning. SJ supervised the project. JM and SJK helped supervise the project. MAsEV led the design of the model. Local knowledge to the model was by EA and AD. MAsEV created the computational framework. SJ, MAJ and MCS analysed the data with support by MAsEV, SJ and MCS. MAJ wrote the manuscript with support from EA, JS-0, B0-0, AD, EAA and 000. SJ serves as garantor for the overall content.

Funding The authors have not declared a specific grant for this research from any funding agency in the public, commercial or not-for-profit sectors.

Competing interests None declared.

Patient consent for publication Not required.

Provenance and peer review Not commissioned; externally peer reviewed.

Data availability statement Data are available in a public, open access repository. All data relevant to the study are included in the article or uploaded as supplemental information. All population estimates and the ancillary spatial datasets and are available online.

Supplemental material This content has been supplied by the author(s). It has not been vetted by BMJ Publishing Group Limited (BMJ) and may not have been peer-reviewed. Any opinions or recommendations discussed are solely those of the author(s) and are not endorsed by BMJ. BMJ disclaims all liability and responsibility arising from any reliance placed on the content. Where the content includes any translated material, BMJ does not warrant the accuracy and reliability of the translations (including but not limited to local regulations, clinical guidelines, terminology, drug names and drug dosages), and is not responsible for any error and/or omissions arising from translation and adaptation or otherwise.

Open access This is an open access article distributed in accordance with the Creative Commons Attribution Non Commercial (CC BY-NC 4.0) license, which permits others to distribute, remix, adapt, build upon this work non-commercially, and license their derivative works on different terms, provided the original work is properly cited, appropriate credit is given, any changes made indicated, and the use is non-commercial. See: http://creativecommons.org/licenses/by-nc/4.0/.

\section{ORCID iDs}

Makela Cordero Stankey http://orcid.org/0000-0002-9140-366X

Justina Seyi-0lajide http://orcid.org/0000-0003-4481-8528

Emmanuel A Ameh http://orcid.org/0000-0003-2386-3039

\section{REFERENCES}

1 Butler EK, Tran TM, Nagarajan N, et al. Epidemiology of pediatric surgical needs in low-income countries. PLoS One 2017;12:e0170968.

2 Meara JG, Leather AJM, Hagander L, et al. Global surgery 2030: evidence and solutions for achieving health, welfare, and economic development. The Lancet 2015;386:569-624.

3 Bickler SW, Rode H. Surgical services for children in developing countries. Bull World Health Organ 2002;80:829-35.

4 Juran S, Broer PN, Klug SJ, et al. Geospatial mapping of access to timely essential surgery in sub-Saharan Africa. BMJ Glob Health 2018;3:e000875.

5 Butler EK, Tran TM, Nagarajan N, et al. Epidemiology of pediatric surgical needs in low-income countries. PLoS One. 2017;12:e0170968. 
6 Butler EK, Tran TM, Fuller AT, et al. Quantifying the pediatric surgical need in Uganda: results of a nationwide cross-sectional, household survey. Pediatr Surg Int 2016;32:1075-85.

7 Ozgediz D, Poenaru D. The burden of pediatric surgical conditions in low and middle income countries: a call to action. $J$ Pediatr Surg 2012;47:2305-11.

8 Lancet Commission Indicator Round 1. Available: https://b6cf2cfdeb09-4859-92a9-a8f002c3bcef.filesusr.com/ugd/346076_a3361c77 f2b24e64bb0cf76eaf9cd61d.pdf

9 Eze TC, Okpala CS, Sunday C. Patterns of Inequality in Human Development Across Nigeria's Six Geopolitical Zones. Developing Country Studies www.iiste.org 2014 www.iiste.org

10 United Nations, Department of Economic and Social Affairs, Population Division. World population prospects. The 2018 revision, online edition, 2018. Available: https://population.un.org/wpp/ DataQuery/

11 United Nations, Department of Economic and Social Affairs, Population Division. World urbanization prospects: the 2018 revision, 2018.

12 UNICEF. The State of the World's Children 2019. Children, Food and Nutrition: Growing well in a changing world. New York: UNICEF, 2019. https://www.unicef.org/sites/default/files/2019-12/SOWC-2019.pdf

13 Ekure EN, Esezobor Cl, Balogun MR, et al. Paediatrician workforce in Nigeria and impact on child health. Niger $\mathrm{J}$ Paediatr 2013;40:112-8.

14 Seyi-Olajide JO, Ameh EA. Investing in pediatric surgical research to advance universal health coverage for children in Nigeria. Niger $J$ Surg 2020;26:1-8

15 Nigeria Federal Ministry of Health. National Surgical, Obstetrics, Anaesthesia \& Nursing Plan (NSOANP) for Nigeria Strategic Priorities for Surgical Care (StraPS) Planning for a Future of Surgical Equity, Safety \& Progress 2019

16 WorldPop. Bottom-Up gridded population estimates for individual age-sex groups in Nigeria, version 1.2.1. WorldPop, University of Southampton 2020

17 Geo-Referenced infrastructure and demographic data for development. Available: https://grid3.gov.ng/datasets [Accessed 28 Feb 2021].
18 Stevens FR, Gaughan AE, Linard C, et al. Disaggregating census data for population mapping using random forests with remotelysensed and ancillary data. PLoS One 2015;10:e0107042.

19 National Aeronautics and space administration. Available: https:// terra.nasa.gov/data/aster-data [Accessed 28 Feb 2021]

20 Open street MAP. Available: https://www.openstreetmap.org/export\# map=8/8.420/-80.113 [Accessed 28 Feb 2021].

21 Humanitarian data exchange. Available: https://data.humdata.org/ dataset/wfp-geonode-nigeria-road-network-main-roads [Accessed 28 Feb 2021]

22 HydroSHEDS (Hydrological data and maps based on SHuttle Elevation Derivatives at multiple Scales) - Africa river network (streamlines) at 30s resolution (Data Basin Dataset). Available: https://www.arcgis.com/home/item.html?id=87b95a603fb74642a2f2 89ec5734a4a1 [Accessed 28 Feb 2021].

23 Páez A, Anjum Z, Dickson-Anderson SE, et al. Comparing distance, time, and metabolic energy cost functions for walking accessibility in infrastructure-poor regions. J Transp Geogr 2020;82:102564.

24 Ebener S, Stenberg K, Brun M, et al. Proposing standardised geographical indicators of physical access to emergency obstetric and newborn care in low-income and middle-income countries. BMJ Glob Health 2019;4:e000778.

25 Hamad D, Yousef Y, Caminsky NG, et al. Defining the critical pediatric surgical workforce density for improving surgical outcomes: a global study. J Pediatr Surg 2020;55:493-512.

26 Davies $\mathrm{JI}$, Vreede $\mathrm{E}$, Onajin-Obembe $\mathrm{B}$, et al. What is the minimum number of specialist anaesthetists needed in low-income and middle-income countries? BMJ Glob Health 2018;3:e001005.

27 Kelly C, Hulme C, Farragher T, et al. Are differences in travel time or distance to healthcare for adults in global North countries associated with an impact on health outcomes? A systematic review. BMJ Open 2016;6:e013059.

28 Grabski D, Ameh EA, Ozgediz D, et al. Optimal resources for children's surgical care: Executive summary. World J Surg 2019;43:978-80. 